\title{
Gold-Nanoparticle Decorated Graphene-Nanostructured Polyaniline Nanocomposite-Based Bienzymatic Platform for Cholesterol Sensing
}

\author{
Deepshikha Saini, ${ }^{1}$ Ruchika Chauhan,, ${ }^{2}$ Pratima R. Solanki, ${ }^{3}$ and T. Basu ${ }^{2}$ \\ ${ }^{1}$ Amity Institute of Biotechnology, Amity University, Uttar Pradesh, Noida 201303, India \\ ${ }^{2}$ Amity Institute of Nanotechnology, Amity University, Uttar Pradesh, Noida 201303, India \\ ${ }^{3}$ Biomedical Instrumentation Section, Department of Science \& Technology Centre on Biomolecular Electronics, \\ National Physical Laboratory, Dr K. S. Krishnan Marg, New Delhi 110012, India \\ Correspondence should be addressed to T. Basu, basu002@yahoo.com \\ Received 9 April 2012; Accepted 29 May 2012 \\ Academic Editors: J. Sha and Y. Zhang
}

Copyright ( $\odot 2012$ Deepshikha Saini et al. This is an open access article distributed under the Creative Commons Attribution License, which permits unrestricted use, distribution, and reproduction in any medium, provided the original work is properly cited.

A novel nanobiocomposite bienzymatic amperometric cholesterol biosensor, coupled with cholesterol oxidase (ChOx) and horseradish peroxidase (HRP), was developed based on the gold-nanoparticle decorated graphene-nanostructured polyaniline nanocomposite (NSPANI-AuNP-GR) film which was electrochemically deposited onto indium-tin-oxide (ITO) electrode from the nanocomposite (NSPANI-AuNP-GR) dispersion, as synthesized by in situ polymerization technique. The gold nanoparticledecorated graphene-nanostructured polyaniline nanocomposite (NSPANI-AuNP-GR) offers an efficient electron transfer between underlining electrode and enzyme active center. The bienzymatic nanocomposite bioelectrodes ChOx-HRP/NSPANI-AuNPGR/ITO have exhibited higher sensitivity, linearity, and lower $K_{m}$ value than monoenzymatic bioelectrode (ChOx/NSPANIAuNP-GR/ITO). It is inferred that bienzyme-based nanobioelectrodes offer wider linearity (35 to $500 \mathrm{mg} / \mathrm{dL}$ ), higher sensitivity $\left(0.42 \mu \mathrm{AmM}^{-1}\right)$, low $\mathrm{km}$ value of $0.01 \mathrm{mM}$ and higher accuracy for testing of blood serum samples than monoenzyme system. Mechanism of the overall biochemical reaction has been proposed to illustrate the enhanced biosensing performance of the bienzyme system. The novelty of the electrode lies on reusability, extended shelf life, and accuracy of testing blood serum samples.

\section{Introduction}

Graphene, one of the most exciting nanostructures of carbon, is a two-dimensional honeycomb crystalline single layer of carbon lattice [1-3]. Recently, it has received enormous interest in various areas of research, such as biosensors, bioelectronics, energy storage and conversion, drug delivery [47], molecular resolution sensors [8-10], ultrafast electronic devices, [11], and electromechanical resonators [5], owing to its large specific surface area, extraordinary electrical and thermal conductivities $[11,12]$, high mechanical stiffness [13], good biocompatibility [14], and low manufacturing cost [15]. The high electrical and thermal conductivities of graphene originate from the extended long-range $\pi$ conjugation.
Out of all conducting polymers, polyaniline (PANI) is one of the promising matrixes for biosensor applications due to its simple and reversible acid/base doping/dedoping chemistry enabling control over properties such as free volume [16], solubility [17], electrical conductivity [18], and optical activity [19]. In recent years, nanostructured polyaniline (NSPANI) has aroused much scientific interest since it combines the properties of low-dimensional organic conductors and high-surface-area materials and offers the possibility of enhanced performance wherever a large interfacial area between NSPANI and its environment is required. Various strategies are employed for the synthesis of nanostructured polyaniline [20-22].

Noble metal nanoparticles are known to be excellent catalysts, due to their high ratio of surface atoms with free 
valences to the cluster of total atoms. As well known, gold nanoparticles (AuNP) have many unique properties such as high surface free energy, strong adsorption ability, well suitability, and good conductivity $[23,24]$. Besides, it can provide more binding sites and more congenial microenvironment for biomolecules immobilization to retain the bioactivity of the proteins, which can prolong the life time of biosensor $[25,26]$. Nanocomposites based on metal nanoparticles and exfoliated graphene nanosheet (GR) with synergistic effect have exhibited particular promise in biosensing characteristics as they can play very interesting role such as (1) a biocompatible enzyme friendly platform, (2) fast electrocatalytic oxidation or reduction of the product generated during biochemical recognition process at the electrode surface to reduce overvoltage and avoid interference from other coexisting electroactive species, and (3) an enhanced signal because of its fast electron transfer and large working surface area. Lu et al. have reported highly sensitive and selective amperometric glucose biosensor using exfoliated graphite nanoplatelets decorated with Pt and Pd nanoparticles [27]. Beside that, graphene-based nanocomposites have been exploited to fabricate alcohol dehydrogenase biosensors for glucose, alcohol, and so forth [2833]. Biosensors, based on graphene-encapsulated nanoparticle arrays, for highly sensitive and selective detection of breast cancer biomarkers are successfully demonstrated. The increased surface-to-volume ratio significantly has helped in lowering the detection limits $(1 \mathrm{pM})$ for the target biomarkers [34]. A glucose electrochemical biosensor has been reported based on zinc oxide nanoparticles $(\mathrm{ZnO}$ NPs) doped in graphene (GR) nanosheets. The results show that the linear response range of the biosensor lies between 0.1 to $20 \mu \mathrm{M}$ and the detection limit has been calculated as $0.02 \mu \mathrm{M}$ at a signal-to-noise ratio of 3 [35].

Cholesterol and its ester are essential constituents of all animal cells, and it is present in brain and nerve tissues. The level of cholesterol in serum is an important parameter in the diagnosis and prevention of heart diseases. The development of electrochemical biosensor received significant interest for precise and smart determination of cholesterol in serum and food sample [36]. However, the so far developed cholesterol biosensors suffer from reliability, poor shelf life, and low sensitivity. Therefore, it is needed to pay attention to the above challenges in order to fabricate a reliable cholesterol biosensor for clinical diagnosis. There are two key factors in the fabrication of a biosensor, firstly enzyme system and secondly transducer matrix to monitor biosensor performance. In amperometric biosensor, cholesterol quantification is usually performed by measurement of the current associated with the oxidation of hydrogen peroxide. One of the major drawbacks of electrochemical biosensor is the overpotential necessary for the oxidation of $\mathrm{H}_{2} \mathrm{O}_{2}$ which can cause interferences from other oxidizable species such as ascorbic acid (AA), uric acid (UA), and acetaminophen (AAP). To avoid interferences, some improved biosensors based on the coupled enzyme reactions have been reported to detect hydrogen peroxide at low potential $[37,38]$. In such cases, the primary product that is produced by the reaction of the analyte with the first enzyme is further converted by a second enzyme to produce products detectable by a transducer [39]. Coupled enzyme reactions are also employed to filter out chemical signals by eliminating the interference on the enzyme [40, 41 .

In the previous communication, the authors have reported an in situ preparation and characterization of novel nanocomposite NSPANI-AuNP-GR dispersion based on NSPANI, graphene nanosheet and gold nanoparticles (NSPANI-AuNP-GR) with high electrocatalytic activity [42]. It has been observed out that the NSPANI-AuNP-GR nanocomposite dispersion can be successfully electrodeposited on the ITO surface. In the paper, attempt has been made to develop a reliable and reusable amperometric bienzymatic cholesterol biosensor based on nanocomposite film on ITO electrode for estimation of free cholesterol. In order to achieve the commercial viability, the developed electrochemical biosensor performance has been compared with photometric technique and tested on blood serum sample of various pathological labs. The novelty of the sensor lies on the method of fabrication of transducer matrix coupled with enzyme system, reusability, reliability, extended shelf life, sensitivity, and successful application to blood serum testing.

\section{Experimental}

2.1. Materials. Few-layered graphene (Quantum Materials Corporation, Bangalore), aniline (Sigma-Aldrich), sodium dodecyl sulphate (SDS) (Qualigen), ammonium persulfate $\left(\mathrm{NH}_{4}\right)_{2} \mathrm{~S}_{2} \mathrm{O}_{8}$ (E-Merck), hydrochloric acid (Qualigen), and chloroauric acid $\mathrm{HClO}_{4}$ (Sigma-Aldrich) were used in the present experiment. Cholesterol oxidase (ChOx; EC 1.1.36, from Pseudomonas fluorescens) with specific activity of $24 \mathrm{U} / \mathrm{mg}$ and horseradish peroxidase (HRP, E.C1.11.1.7, $250 \mathrm{U} / \mathrm{mg}$, from Horseradish) were purchased from Sigma, potassium ferricyanide $\left(\mathrm{K}_{3}\left[\mathrm{Fe}(\mathrm{CN})_{6}\right]\right)$, potassium ferrocyanide $\left(\mathrm{K}_{4}\left[\mathrm{Fe}(\mathrm{CN})_{6}\right]\right)$, sodium dihydrogen orthophosphate $\left(\mathrm{NaH}_{2} \mathrm{PO}_{4}\right)$, and disodium hydrogen orthophosphate $\left(\mathrm{Na}_{2} \mathrm{HPO}_{4}\right)$ were purchased from Qualigens (India). Deionized water from a Millipore-MilliQ was used in all cases to prepare aqueous solutions. Monomer was double distilled before polymerization.

\subsection{Characterization and Measurement. Fourier transform} infrared spectroscopic (FTIR) measurements were performed with a Perkin-Elmer FTIR spectrophotometer. Morphological imaging of the fabricated electrodes was obtained by scanning electron microscope (LEO 440 Model), and atomic force microscopy (AFM) was performed by Park Systems XE-70 Atomic Force Microscope in noncontact mode. Cyclic voltammetry and differential pulse voltammetry (DPV) measurements were conducted in phosphate buffer $(50 \mathrm{mM}, 0.9 \% \mathrm{NaCl})$ containing $5 \mathrm{mM}[\mathrm{Fe}(\mathrm{CN}) 6]^{3-/ 4-}$ in a three-electrode cell consisting of $\mathrm{Ag} / \mathrm{AgCl}$ as reference, platinum $(\mathrm{Pt})$ as counter electrode and ITO as a working 
electrode $\left(0.25 \mathrm{~cm}^{2}\right)$ using Autolab Potentiostat/Galvanostat Model AUT83945 (PGSTAT302N).

\subsubsection{Synthesis of Gold-Nanoparticle-Decorated Graphene-Nanostructured Polyaniline Nanocomposite (NSPANI-AuNP-GR)}

Synthesis of NSPANI-AuNP-GR Nanodispersion. In a typical synthesis, graphene was first dispersed into a dilute aqueous solution of sodium dodecyl sulphate (SDS) $(0.02 \mathrm{M})$. The aniline solution in the dopant $(0.02 \mathrm{M})$ was added to an aqueous solution of SDA under stirring condition. The mixture was then placed in the low temperature bath, so that the temperature was maintained at $0^{\circ}$ to $5^{\circ} \mathrm{C} .70 \mu \mathrm{L}$ aqueous solution of $0.05 \mathrm{M} \mathrm{HAuCl}_{4}$ was added into aqueous dispersion. An aqueous solution of the oxidizing agent, $\left(\mathrm{NH}_{4}\right)_{2} \mathrm{~S}_{2} \mathrm{O}_{8}$, in ice-cold water was added to the above mixture. The polymerization was allowed to proceed for 3 to $4 \mathrm{~h}$ with stirring. After that the stirring was stopped and the mixture was kept under static condition for 1-3 days at $277-278^{\circ} \mathrm{K}$ for polymerization to complete. Thus, NSPANIAuNP-GR nanodispersion was prepared by in situ polymerization as characterized in our previous communication [42].

2.3. Fabrication of NSPANI-AuNP-GR/ITO Electrodes. The NSPANI-AuNP-GR nanocomposite film was electrochemically deposited from NSPANI-AuNP-GR nanocomposite dispersion as synthesized, onto ITO-coated glass plates by sweeping a potential from $-200 \mathrm{mV}$ to $+1000 \mathrm{mV}$ (versus $\mathrm{Ag} / \mathrm{AgCl}$ ) at a scan rate of $40 \mathrm{mV} / \mathrm{s}$ in a three-electrode cell consisting of $\mathrm{Ag} / \mathrm{AgCl}$ as reference, platinum $(\mathrm{Pt})$ as counter electrode, and ITO as a working electrode $\left(0.25 \mathrm{~cm}^{2}\right)$. The electrodeposition curves of NSPANI-AuNP-GR/ITO exhibit characteristics electrochemistry for NSPANI [33] with the main peaks $\mathrm{a}$ and $\mathrm{b}$ corresponding to the transformation of leucoemeraldine base (LB) to emeraldine salt (ES) and ES to pernigraniline salt (PS), respectively. On the reverse scan, peaks $\mathrm{b}^{\prime}$ and $\mathrm{a}^{\prime}$ correspond to the conversion of PS to ES and ES to LB, respectively. The presence of a small redox peak around $+350 \mathrm{mV}\left(\mathrm{C}\right.$ and $\left.\mathrm{C}^{\prime}\right)$ is associated with the formation of $p$-benzoquinone and hydroquinone as a side product upon cycling the potential to $+1000 \mathrm{mV}$. The increase in current density with successive scans suggests that the polymer film builds up on the electrode surface. Figure 1 inset shows the plot of maximum anodic peak current versus with number of cycles. Maximum peak current was observed at 28 cycles indicating a continuous film deposition. It can also be observed that the shifts in peak potentials began to occur after a number of cycles. This may be the result of increased resistance of the electrode, as the film deposited becomes thicker. The current has reached up to $0.261 \mathrm{~mA} \mathrm{~cm}^{-2}$ for 28 cycles during electrodeposition of the nanocomposite dispersion. On further increase in number of cycles, anodic peak current decreases. This decrease in peak current is ascribed to the degradation of polymer film. In the present study, 28 cycles were used for film deposition for biosensor application.

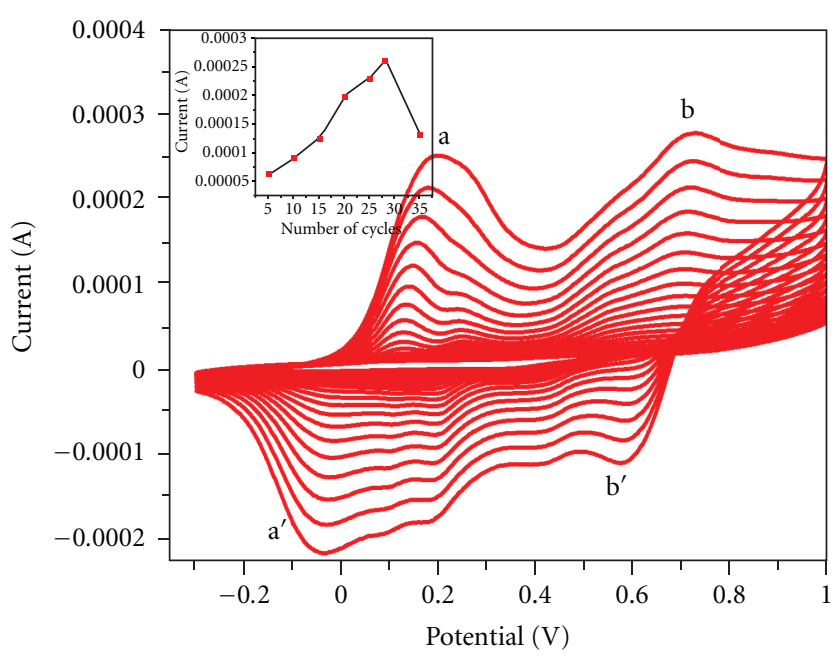

FIGURE 1: Electrodeposition of NSPANI-AuNP-GR nanocomposite dispersion on the ITO electrode. Inset: Plot of peak current against number of cycles.

2.3.1. Fabrication of ChOx/NSPANI-AuNP-GR/ITO and ChOx-HRP/NSPANI-AuNP-GR Nanobioelectrodes. The NSPANI-AuNP-GR/ITO electrode was treated with $10 \mu \mathrm{L}$ of aqueous glutaraldehyde $(0.1 \%)$ as a cross-linker. $10 \mu \mathrm{L}$ of freshly prepared ChOx $(1 \mathrm{mg} / \mathrm{mL})$ was uniformly spread onto glutaraldehyde-treated NSPANI-AuNP-GR/ITO electrode and is kept in a humid chamber for $12 \mathrm{~h}$ at $4^{\circ} \mathrm{C}$ to fabricate ChOx/NSPANI-AuNP-GR/ITO nanobioelectrode. $10 \mu \mathrm{L}$ freshly prepared solution of HRP $(1 \mathrm{mg} / \mathrm{mL}$ and ChOx $(1 \mathrm{mg} / \mathrm{mL}) \quad(1: 1)$ was uniformly spread onto glutaraldehyde-treated NSPANI-AuNP-GR/ITO electrode and was kept in a humid chamber for $12 \mathrm{~h}$ at $4^{\circ} \mathrm{C}$ to prepare ChOx/NSPANI-AuNP-GR/ITO and ChOx-HRP/NSPANIAuNP-GR/ITO bioelectrodes. The bioelectrodes were immersed in $5 \mathrm{mM}$ phosphate buffer solution ( $\mathrm{pH}$ 7.0) in order to wash out unbound enzyme from the electrode surface. When not in use, the electrode was stored at $4^{\circ} \mathrm{C}$ in a refrigerator.

2.4. Preparation of Solutions. Stock solution of cholesterol was prepared in deionized water having $10 \%$ Triton X-100 and was stored at $4{ }^{\circ} \mathrm{C}$. This stock solution was further diluted to make different concentrations of cholesterol solution. $o$ Dianisidine (1\%) solution was prepared freshly in deionized water. Buffers of various $\mathrm{pH}$ values were prepared by dissolving different ratios of sodium dihydrogen orthophosphate $\left(\mathrm{NaH}_{2} \mathrm{PO}_{4}\right)$ and disodium hydrogen orthophosphate $\left(\mathrm{Na}_{2} \mathrm{HPO}_{4}\right)$ in Millipore water.

2.5. Photometric Studies. Photometric measurements were conducted using a UV-visible spectrophotometer. Photometric experiments were carried out with cholesterol solution using PBS buffer ( $50 \mathrm{mM}, 0.9 \% \mathrm{NaCl}, \mathrm{pH} 7.4$ ). To carry out photometric enzymatic assay of the immobilized enzyme, ChOx/NSPANI-AuNP-GR/ITO and ChOx-HRP/NSPANIAuNP-GR/ITO bioelectrodes were dipped in $3 \mathrm{~mL}$ of PBS 


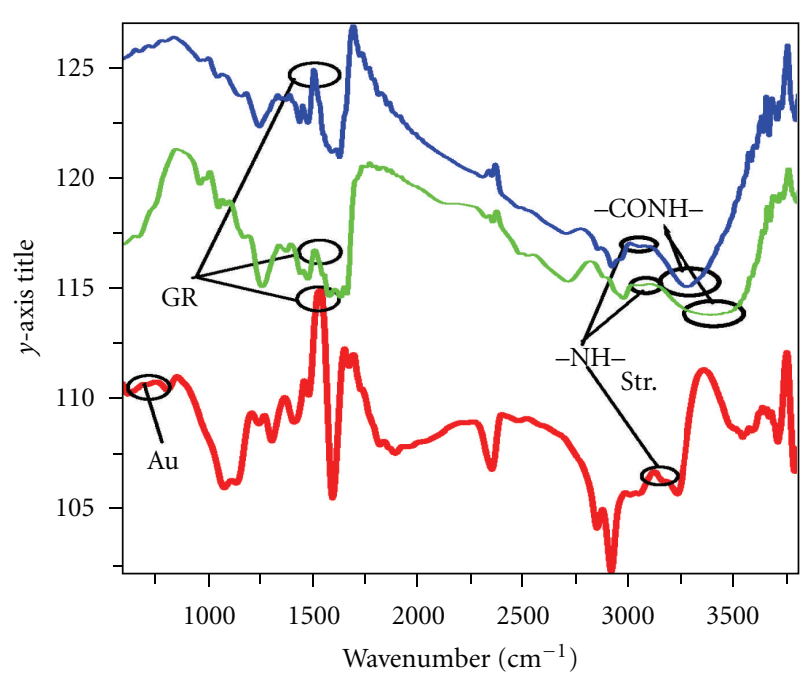

FIGURE 2: FTIR spectra of (a) NSPANI-AuNP-GR/ITO (red colour), (b) ChOx/NSPANI-AuNP-GR/ITO (green colour), (c) ChOxHRP/NSPANI-AuNP-GR electrodes (blue colour).

solution containing $20 \mu \mathrm{L}$ of HRP ( $1 \mathrm{mg} \mathrm{dL} / 1), 20 \mu \mathrm{L}$ of $o$ dianisidine dye, and $100 \mu \mathrm{L}$ of cholesterol. The difference between the initial and final absorbance values at $500 \mathrm{~nm}$ after 3 min incubation of cholesterol was recorded and plotted.

\section{Discussion}

\subsection{Characterization of NSPANI-AuNP-GR/ITO, ChOx/NSPANI-AuNP-GR/ITO, and ChOx-HRP/NSPANI-AuNP-GR Electrodes}

(a) FT-IR Study. Figure 2 represents the FT-IR absorption spectra of the NSPANI-AuNP-GR/ITO (curve a), ChOx/ NSPANI-AuNP-GR/ITO (curve b), and ChOx-HRP/ NSPANI-AuNP-GR (curve c) electrodes. The FT-IR spectrum of electrochemically deposited NSPANI-AuNP-GR/ ITO nanocomposite (curve a) shows benzenoid and quinoid ring stretching bands $(\mathrm{C}=\mathrm{C})$ present at $1447.6 \mathrm{~cm}^{-1}$ and $1560 \mathrm{~cm}^{-1}$. The presence of peak at $3123 \mathrm{~cm}^{-1}$ is attributed to $-\mathrm{N}-\mathrm{H}$ stretching vibrations of NSPANI in the composite [43]. A peak at $1534 \mathrm{~cm}^{-1}$ due to the skeletal vibration of graphene nanosheet is observed [44] in the FT-IR spectra of NSPANI-AuNP-GR/ITO (curve a). In the FTIR spectra, apart from the above-mentioned functional groups, a peak appears at $655 \mathrm{~cm}^{-1}$ which may correspond to stretching vibration of $\mathrm{Au}-\mathrm{O}-\mathrm{Au}$ [44]. The presence of these peaks reveals the existence of NSPANI, graphene nanosheet, and AuNPs on the ITO electrode. In the FT-IR spectrum of ChOx/NSPANI-AuNP-GR/ITO and ChOx-HRP/NSPANIAuNP-GR bioelectrode (Figures 2(b) and 2(c)), enzyme binding is indicated by the appearance of additional absorption bands at 1524 and $1630 \mathrm{~cm}^{-1}$ assigned to the carbonyl stretch (amide I band) and $\mathrm{N}-\mathrm{H}$ bending (amide II band), respectively [45]. Also, a broadband seen around $3560 \mathrm{~cm}^{-1}$ is attributed to amide bond present in $\mathrm{ChOx}$ [46]. (b) SEM Study. SEM images of NSPANI-AuNP-GR/ITO (Figure 3(a)), ChOx/NSPANI-AuNP-GR/ITO (Figure 3(b)), and ChOx-HRP/NSPANI-AuNP-GR (Figure 3(c)) are shown in Figure 3. The electrodeposition of NSPANI-AuNP-GR matrix on ITO electrode has been confirmed by the homogeneous rough surface (Figure 3(a)). SEM image shows NSPANI deposited on a few-layered graphene nanosheet which provide large surface area for the incorporation of metal nanoparticles. SEM image reveals the uniform loading of AuNP over NSPANI-GR matrix (Figure 3(c)) [44]. The nanoscale surface roughness of the NSPANI-AuNP-GR nanocomposite film is suitable for the immobilization of biomolecules. From the Figures 3(b) and 3(c), it is found that the enzymes are uniformly distributed on the electrode surfaces. The surface morphology of ChOx/NSPANI-AuNPGR/ITO (Figure 3(b)) and ChOx-HRP/NSPANI-AuNP-GR (Figure 3(c)) shows full coverage of the surface by the single and bienzyme bioconjugates. The presence of globular structure can be attributed to the covalently bound enzyme molecule since most of the proteins and enzymes possess globular structure $[47,48]$.

(c) AFM Study. AFM is employed to establish the thickness, surface morphology, and surface roughness of the NSPANI-AuNP-GR/ITO and ChOx-HRP/NSPANI-AuNPGR/ITO electrodes. The two-dimensional (2D) and threedimensional (3D) atomic force microscopy (AFM, Figure 4(a)) studies reveal that film NSPANI-AuNP-GR/ITO $(2 \times 2 \mu \mathrm{m})$ shows nanoporous morphology with roughness (root mean square (RMS)) of about $29.3 \mathrm{~nm}$, though their spherical shape appears to be partially distorted. The size of the spherical nanoparticles varies from 25 to $50 \mathrm{~nm}$ with average particle size of $35 \mathrm{~nm}$. However, after the immobilization of ChOx-HRP, the surface morphology of NSPANI-AuNP-GR/ITO film changes into smooth morphology wherein the average particle size increases to $100 \mathrm{~nm}$ and roughness decreases to $6.1 \mathrm{~nm}$ revealing that ChOx-HRP is adsorbed onto NSPANI-AuNP-GR/ITO (Figure 4(b)) via electrostatic interactions. AFM image of ChOx-HRP/NSPANI-AuNP-GR/ITO bioelectrode $(2 \times$ $2 \mu \mathrm{m})$ exhibits well-arranged uniform surface indicating that NSPANI-AuNP-GR/ITO film provides a desired microenvironment for strong adsorption of ChOx-HRP in a particular orientation and wherein it retains its better configuration with more active sites.

(d) DPV Study. DPV experiments have been conducted in phosphate buffer $(50 \mathrm{mM}, \mathrm{pH} 7.0)$ containing $5 \mathrm{mM}(\mathrm{Fe}$ $\left.\left[\mathrm{Fe}(\mathrm{CN})_{6}\right]^{3-/ 4-}\right)$ in the range -0.4 to $1.2 \mathrm{~V}$ (Figure 5). The high value of maximum anodic peak current obtained as $1.63 \times 10^{-4} \mathrm{~A}$ for NSPANI-AuNP-GR/ITO electrode (curve a) suggests high conducting nature of NSPANI-AuNPGR/ITO electrode and enhanced electron transfer towards the electrode. The magnitude of peak current decreases to $1.32 \times 10^{-4} \mathrm{~A}$ (curve b) and $1.01 \times 10^{-4} \mathrm{~A}$ (curve c) for ChOx-HRP/NSPANI-AuNP-GR/ITO and ChOx/NSPANIAuNP-GR/ITO bioelectrodes, respectively, indicating slow redox process at the nanobioelectrodes due to insulating 


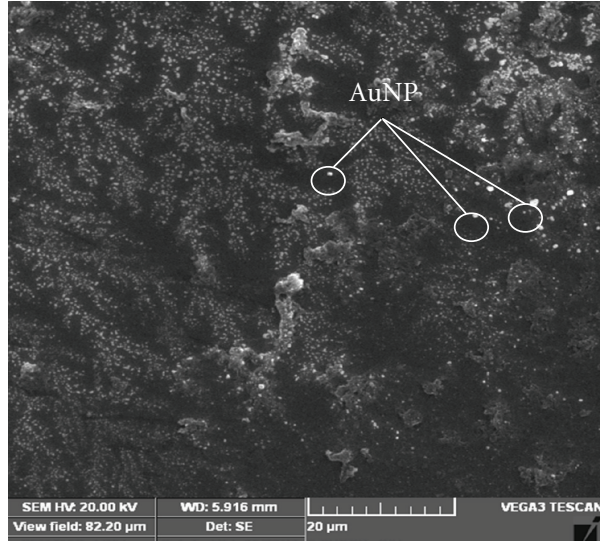

(a)

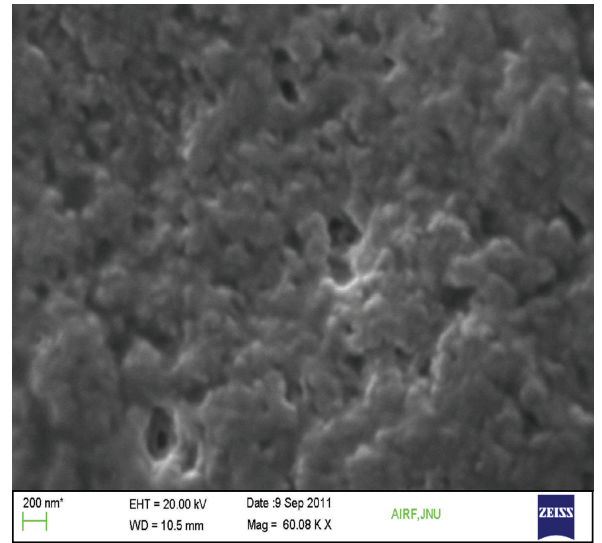

(b)

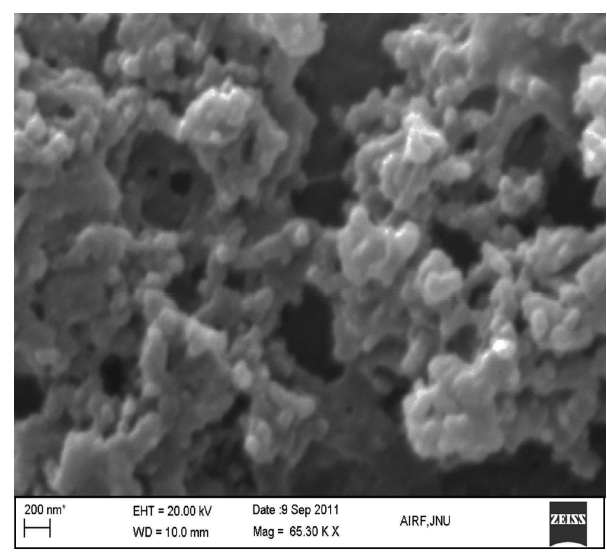

(c)

Figure 3: SEM images of (a) NSPANI-AuNP-GR/ITO, (b) ChOx/NSPANI-AuNP-GR/ITO, and (c) ChOx-HRP/NSPANI-AuNP-GR electrodes.

characteristics of ChOx-HRP and ChOx revealing immobilization of ChOx and ChOx-HRP on NSPANI-AuNPGR/ITO electrode. The magnitude of peak current $(1.32 \times$ $10^{-4} \mathrm{~A}$ ) of ChOx-HRP/NSPANI-AuNP-GR/ITO (curve b) is found to be higher as compared to ChOx/NSPANIAuNP-GR/ITO $\left(1.01 \times 10^{-4} \mathrm{~A}\right)$ (curve c). The enhanced peak current indicates the increased surface activeness of the bioelectrode and increased number of electron transfer.

3.2. Electrochemical Response Studies. The DPV curves of ChOx/NSPANI-AuNP-GR/ (Figure 6(a)) and ChOx-HRP/ NSPANI-AuNP-GR/ITO (Figure 6(b)) bioelectrodes recorded in the range of -0.4 to $1.2 \mathrm{~V}$ using phosphate buffer of pH 7.0 containing $5 \mathrm{mM}\left[\mathrm{Fe}(\mathrm{CN})_{6}\right]^{3-/ 4-}$ and cholesterol solution of various concentration are shown in Figure 6. Change in current $(\Delta \mathrm{I})$ is plotted against cholesterol concentration values. A linear relationship between the cholesterol concentration and the increase in response current $(\Delta \mathrm{I})$ for both the mono- as well as bienzyme-based nanobioelectrodes is observed. The linear regression curve (Figure 6(a)) of the ChOx/NSPANI-AuNP-GR/ITO bioelectrode, which is used to detect cholesterol in the range of $35-350 \mathrm{mg} / \mathrm{dL}$, follows the equation $\Delta \mathrm{I}$ (current) $(\mathrm{mA})=0.12(\mathrm{~mA})+0.0031$
$\left(\mathrm{mA} \mathrm{mg} \mathrm{dL} \mathrm{d}^{-1}\right) \times$ cholesterol concentration $\left(\mathrm{mg} \mathrm{dL}^{-1}\right)$ with $99.4 \mu \mathrm{A}$ and 0.981 as standard deviation and correlation coefficient, respectively. The sensitivity of the bioelectrode has been found to be $0.310 \mu \mathrm{A} \mathrm{mg} \mathrm{dL}{ }^{-1}$. The linear equation of ChOx-HRP/NSPANI-AuNP-GR/ITO in Figure 6(b) is represented by the equation $\Delta \mathrm{I}$ (current) $(\mathrm{mA})=0.36$ $(\mathrm{mA})+0.0042\left(\mathrm{~mA} \mathrm{mg} \mathrm{dL}{ }^{-1}\right) \times$ cholesterol concentration $\left(\mathrm{mg} \mathrm{dL}^{-1}\right.$ ) with $65.2 \mu \mathrm{A}$ and 0.995 as standard deviation and correlation coefficient, respectively. Furthermore, the ChOxHRP/NSPANI-AuNP-GR/ITO bioelectrodes exhibit a higher sensitivity of $0.42 \mu \mathrm{A} \mathrm{mg} \mathrm{dL}^{-1}$ than the single enzyme-based electrodes (ChOx/NSPANI-AuNP-GR/ITO) and linear range of $35-500 \mathrm{mg} / \mathrm{dL}$. The response current and sensitivity are higher for bienzymatic sensor than the monoenzymatic nano biosensor suggesting effective reduction of $\mathrm{H}_{2} \mathrm{O}_{2}$ catalyzed by HRP. All of the experiments have been carried out in triplicate sets, and the results reveal reproducibility of the system. The values of response time of (ChOx/NSPANIAuNP-GR/ITO) and (ChOx-HRP/NSPANI-AuNP-GR/ITO) are found to be as 28 and $19 \mathrm{~s}$, respectively, which are measured by measuring the time taken to reach the steadystate current after applying a steady voltage of $250 \mathrm{mV}$ for $100 \mathrm{mg} / \mathrm{dL}$ of cholesterol solution in $7.0 \mathrm{pH}$ PBS buffer containing $5 \mathrm{mM}\left[\mathrm{Fe}(\mathrm{CN})_{6}\right]^{3-/ 4-}$. 

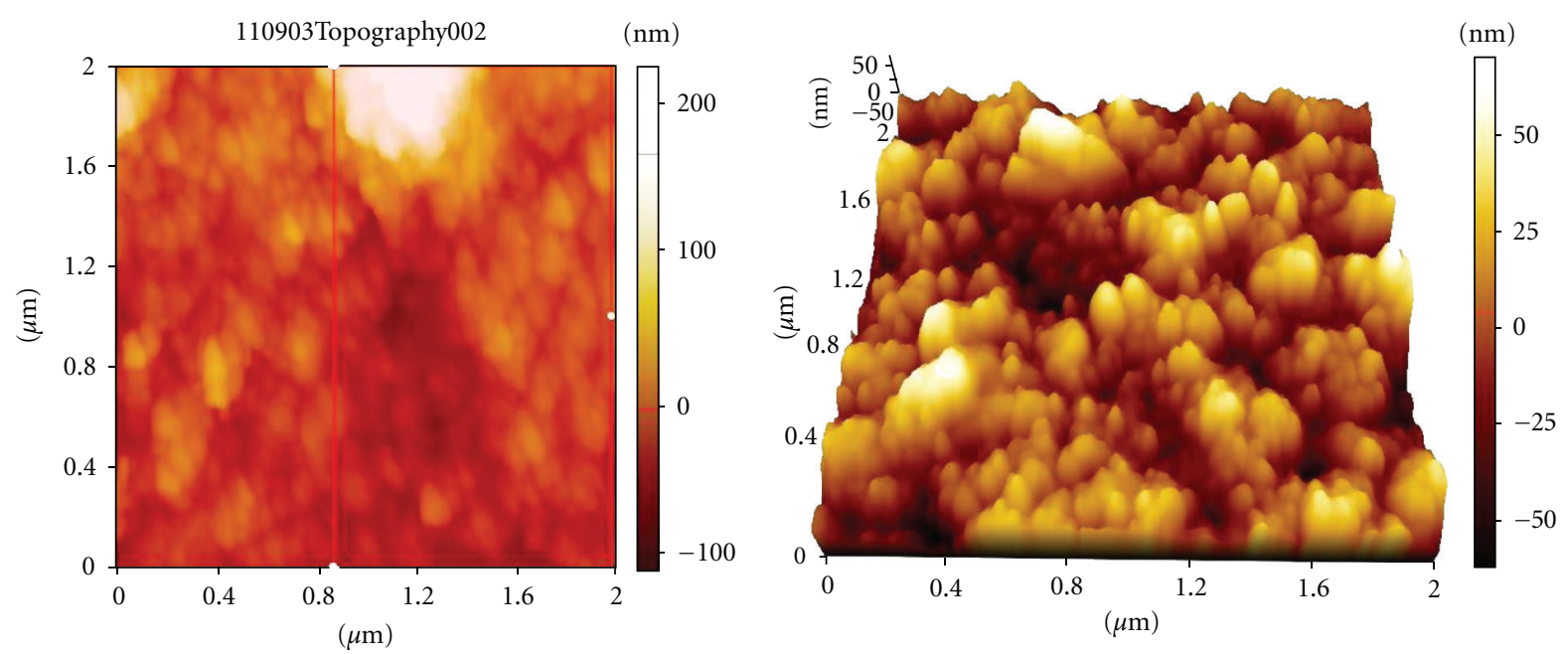

(a)
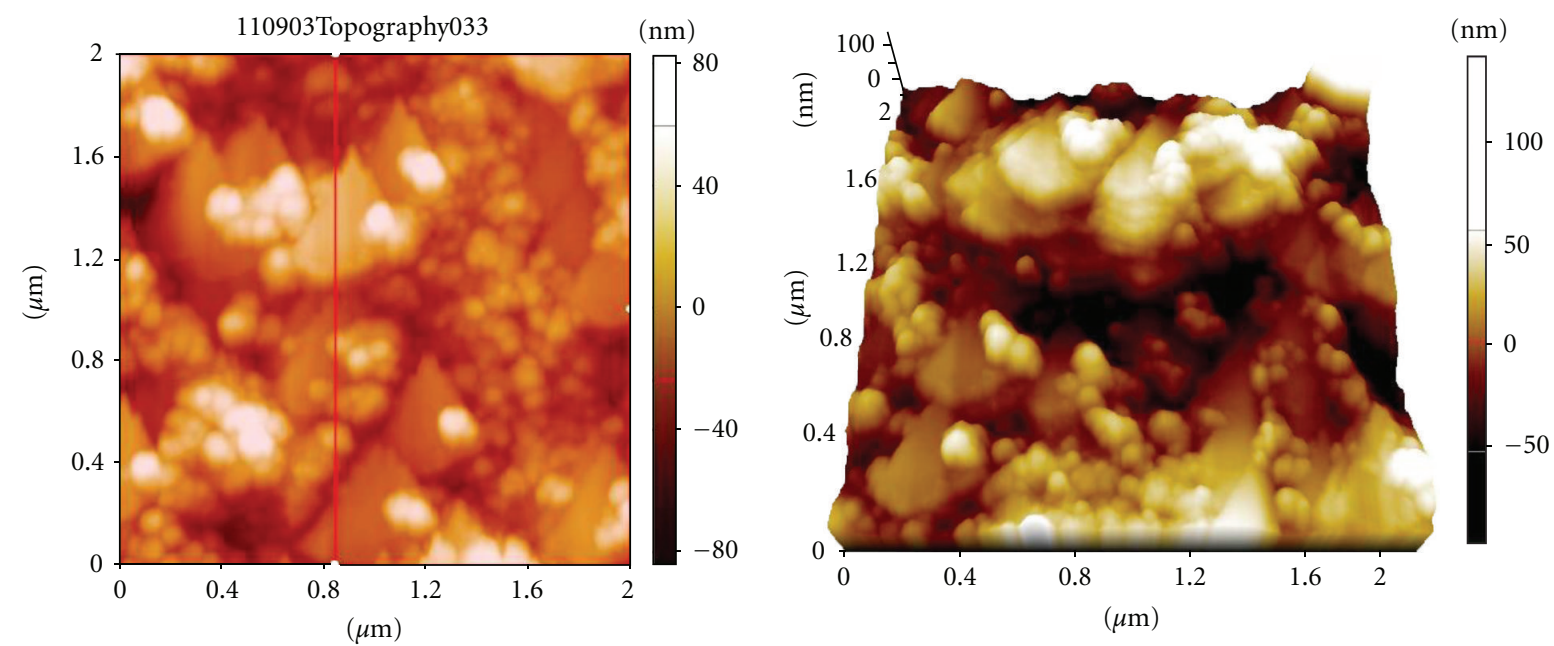

(b)

Figure 4: 2D and 3D AFM images of (a) NSPANI-AuNP-GR/ITO, (b) ChOx-HRP/NSPANI-AuNP-GR electrodes.

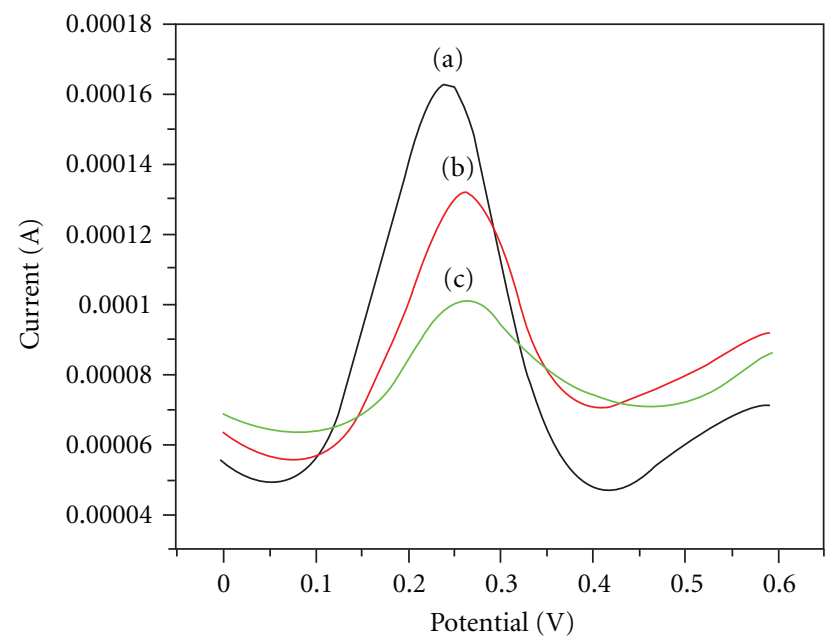

Figure 5: Differential Pulse Voltammetry of (a) NSPANIAuNP-GR/ITO (b) ChOx-HRP/NSPANI-AuNP-GR/ITO (c) ChOx/ NSPANI-AuNP-GR/ITO electrodes.
The value of the enzyme-substrate kinetics parameter (Michaelis-Menten constant, $K_{m}$ ) estimated using the Lineweaver-Burke plot reveals affinity of enzyme for desired analyte. It may be noted that $K_{m}$ is dependent both on matrix and the method of immobilization of enzymes that often results in their conformational changes resulting in different values of $K_{m}$. The $K_{m}$ value was determined by the analysis of the slope and intercept for the plot of the reciprocals of change in current versus cholesterol concentrations, that is, the Lineweaver-Burke plot of $1 / \Delta \mathrm{I}$ versus $1 / C$. The values of apparent Michaelis-Menten constant $\left(K_{m}\right)$ have been estimated using the LineweaverBurke plot for ChOx/NSPANI-AuNP-GR/ITO and ChOxHRP/NSPANI-AuNP-GR/ITO as $0.02 \mathrm{mM}$ and $0.01 \mathrm{mM}$, respectively. The observed lower value of $K_{m}$ for bienzyme system indicates high affinity for cholesterol attributed to the immobilization of ChOx-HRP onto NSPANI-AuNPGR/ITO for faster biochemical reaction. This result can be assigned to the uniform distribution of enzyme molecules on to the NSPANI-AuNP-GR/ITO nanocomposite film surface. 


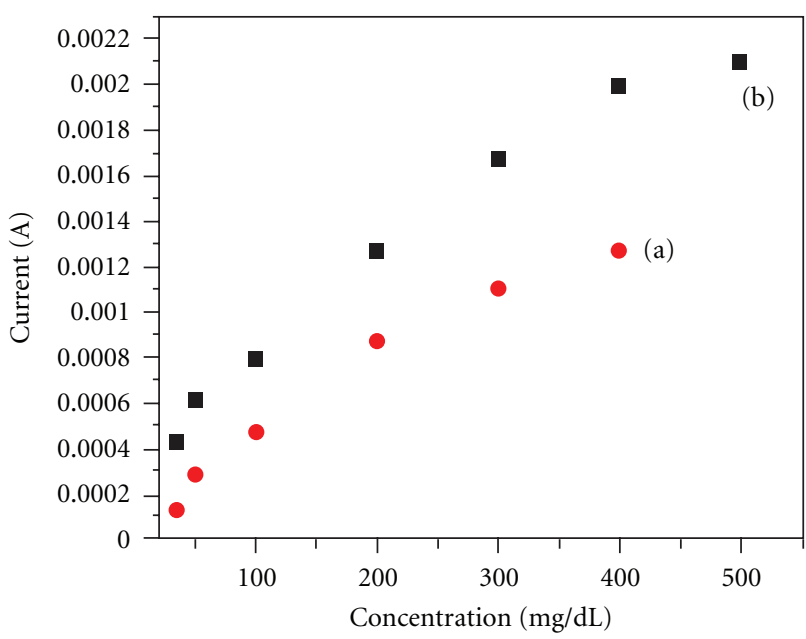

FIgure 6: Calibration curve of (a) ChOx/NSPANI-AuNP-GR/ITO and (b) ChOx-HRP/NSPANI-AuNP-GR/ITO bioelectrodes.

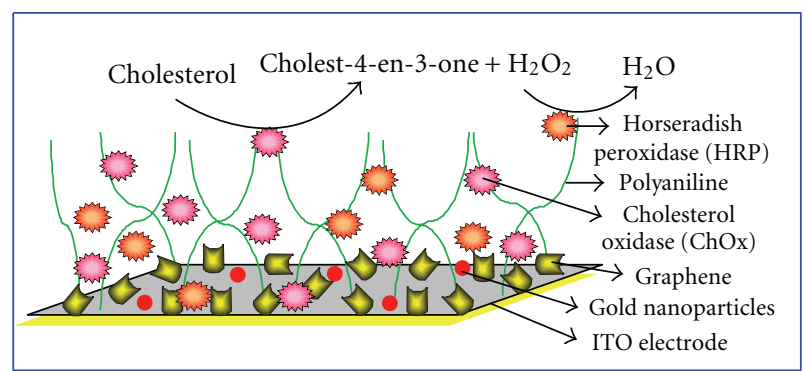

Scheme 1: Proposed biochemical reaction on the ChOx-HRP/ NSPANI-AuNP-GR.

The overall biochemical reaction for ChOx-HRP/NSPANIAuNP-GR is shown by (1)-(5) and Scheme 1.

\section{Chox-HRP/NSPANI-AuNP-GR/ITO}

$$
\begin{array}{r}
\text { Cholesterol }+\mathrm{O}_{2} \longrightarrow \text { Cholest-4-en-3-one }+\mathrm{H}_{2} \mathrm{O}_{2} \\
\mathrm{H}_{2} \mathrm{O}_{2}+\mathrm{HRP}\left(\mathrm{Fe}^{+3}\right) \longrightarrow \mathrm{HRP}-\mathrm{I}\left(\mathrm{Fe}^{+4}\right)+\mathrm{H}_{2} \mathrm{O} \\
\mathrm{HRP}-\mathrm{I}\left(\mathrm{Fe}^{+4)}\right)+\mathrm{Fe}(\mathrm{CN})_{6}{ }^{4-} \longrightarrow \mathrm{HRP}-\mathrm{II}\left(\mathrm{Fe}^{+4}\right) \\
+\mathrm{Fe}(\mathrm{CN})_{6}{ }^{3-} \\
\mathrm{HRP}-\mathrm{II}\left(\mathrm{Fe}^{+4)}\right)+\mathrm{Fe}(\mathrm{CN})_{6}{ }^{3-} \longrightarrow \operatorname{HRP}\left(\mathrm{Fe}^{+3}\right)+ \\
\mathrm{Fe}(\mathrm{CN})_{6}{ }^{4-} \longrightarrow \mathrm{Fe}(\mathrm{CN})_{6}{ }^{4-}+\mathrm{e}
\end{array}
$$

3.3. Photometric Response Studies. The response characteristics of ChOx-HRP/NSPANI-AuNP-GR/ITO and ChOx/ NSPANI-AuNP-GR/ITO bioelectrodes have been studied as a function of cholesterol concentration (Figure 7), and the value of absorbance resulting from the oxidized form of dye

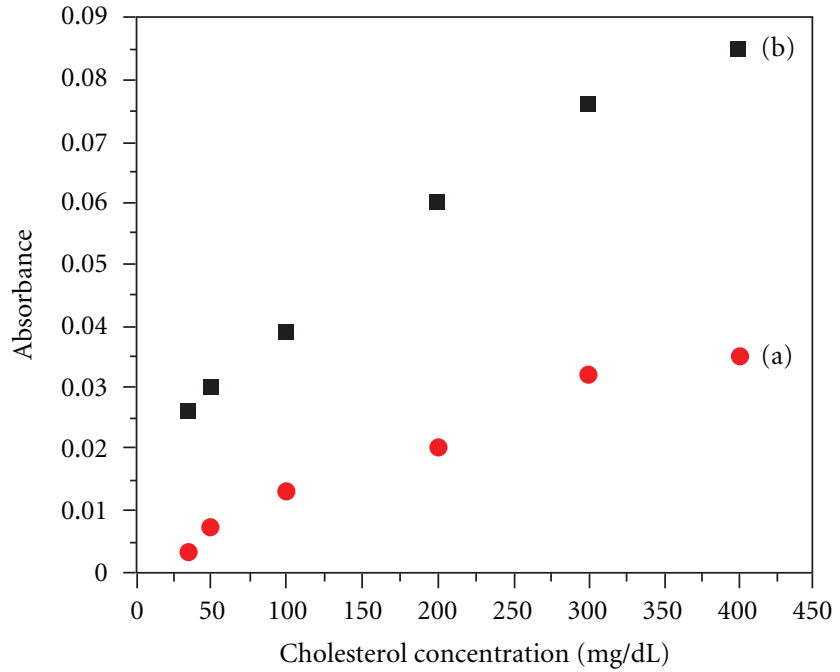

FIgure 7: Photometric response of (a) ChOx/NSPANI-AuNPGR/ITO and (b) ChOx-HRP/NSPANI-AuNP-GR/ITO nanobioelectrodes as a function of cholesterol concentration.

has been found to be increasing linearly with increase in cholesterol concentration for both bioelectrodes. It has been found that the ChOx-HRP/NSPANI-AuNP-GR/ITO bioelectrode in the range of $35-400 \mathrm{mg} / \mathrm{dL}$ for cholesterol concentration follows the equation: Change in absorbance $=0.022$ $+0.00016 \times$ cholesterol concentration $(\mathrm{mg} / \mathrm{dL})$ with 0.003 as standard deviation whereas ChOx/NSPANI-AuNP-GR/ITO bioelectrode in the range of $35-350 \mathrm{mg} / \mathrm{dL}$ for cholesterol concentration follows the equation: Change in absorbance $=0.002+0.000088 \times$ cholesterol concentration $(\mathrm{mg} / \mathrm{dL})$ with 0.0025 as standard deviation. The value of apparent Michaelis-Menten constant $\left(K_{m}\right)$ has been estimated using the Lineweaver-Burk plot, graph between inverse of absorption and inverse of cholesterol concentration. The lower value of $K_{m}(0.012 \mathrm{mM})$ for ChOx-HRP/NSPANI-AuNPGR/ITO biosensor as compared to ChOx/NSPANI-AuNPGR/ITO biosensor $(0.023 \mathrm{mM})$ suggests that the NSPANIAuNP-GR matrix is facilitating the enzymatic reaction.

\subsection{Studies of $p H$, Interference, Reusability, and Shelf Life of Biosensors}

(a) pH Studies. The response current of the ChOx/NSPANIAuNP-GR/ITO and ChOx-HRP/NSPANI-AuNP-GR/ITO nanobioelectrodes studied in the $\mathrm{pH}$ range 6.0-7.8 (data not shown) suggests that both bioelectrodes exhibit maximum activity at around $\mathrm{pH}$ 7.0. At this $\mathrm{pH}$, the biomolecules retain their natural structures and do not get denatured. Thus all experiments have been conducted out at the optimum $\mathrm{pH}$ value of 7.0 for cholesterol estimation.

(b) Interference Studies. Different interferents which are mostly present in blood such as ascorbic acid $(0.05 \mathrm{mM})$, glucose $(5 \mathrm{mM})$, uric acid $(0.1 \mathrm{mM})$, sodium ascorbate $(0.05 \mathrm{mM})$, and urea $(1 \mathrm{mM})$ were tested through the DPV measurements for both biocomposite electrodes such as 
TABLE 1: A comparative evaluation of single and bienzymatic biosensor performance.

\begin{tabular}{lccc}
\hline S. no. & Characteristics & ChOx/NSPANI-AuNP-GR/ITO & ChOx-HRP/NSPANI-AuNP-GR/ITO \\
\hline 1 & Linearity & $35-400 \mathrm{mg} / \mathrm{dL}$ & $35-500 \mathrm{mg} / \mathrm{dL}$ \\
2 & Detection limit & $35 \mathrm{mg} / \mathrm{dL}$ & $25 \mathrm{mg} / \mathrm{dL}$ \\
3 & Response time & $28 \mathrm{secs}$ & $19 \mathrm{secs}$ \\
4 & Sensitivity & $3.10 \mu \mathrm{A} \mathrm{mg} \mathrm{dL}$ & $4.22 \mu \mathrm{Amg} \mathrm{dL}^{-1}$ \\
5 & $K_{m}$ & $0.02 \mathrm{mM}$ & $0.01 \mathrm{mM}$ \\
6 & Shelf life & 8 weeks & 8 weeks \\
\hline
\end{tabular}

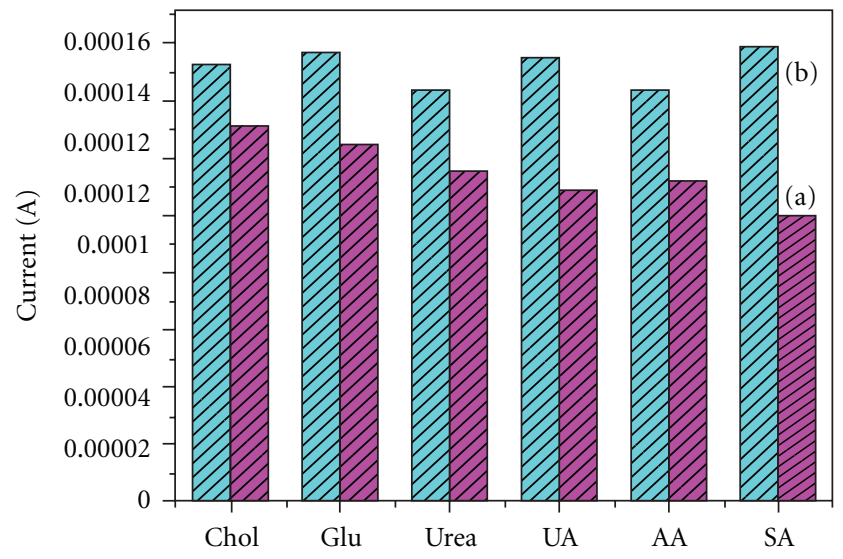

Figure 8: Interferent study of (a) ChOx/NSPANI-AuNP-GR/ITO and (b) ChOx-HRP/NSPANI-AuNP-GR/ITO nanobioelectrodes.

ChOx/NSPANI-AuNP-GR/ITO and ChOx-HRP/NSPANIAuNP-GR/ITO using cholesterol solution (100 mg/dL) in a $1: 1$ ratio. Figure 8 shows the effect of interferents on the observed response of ChOx/NSPANI-AuNP-GR/ITO and ChOx-HRP/NSPANI-AuNP-GR/ITO bioelectrodes. In the Figure 8, the first bar (cholesterol) shows the current obtained with $100 \mathrm{mg} / \mathrm{dL}$ cholesterol. The remaining bars show the current corresponding to the mixture of cholesterol and interferents in a $1: 1$ ratio. The percentage interference (\% interference) was calculated using (6) for various interferents:

$$
\text { \%Interference }=\frac{\left[\Delta \mathrm{I}_{\text {chol }}-\Delta \mathrm{I}_{\text {inter }}\right]}{\left[\Delta \mathrm{I}_{\text {chol }}\right]} \times 100,
$$

where $\Delta \mathrm{I}_{\text {chol }}$ is the change in current obtained with $100 \mathrm{mg} / \mathrm{dL}$ cholesterol and $\Delta \mathrm{I}_{\text {inter }}$ is the change in current corresponding to the mixture of cholesterol and interferents in a $1: 1$ ratio. A maximum of $6 \%$ interference for $\mathrm{ChOx}$ HRP/NSPANI-AuNP-GR/ITO bioelectrode and 9\% interference for ChOx/NSPANI-AuNP-GR/ITO bioelectrode are observed.

(c) Reusability Studies. The unique feature of both types of bioelectrodes is their reusability (Figure 9) which is attributed due to composition of the transducer matrix. It has been found that ChOx/NSPANI-AuNP-GR/ITO and ChOx-HRP/NSPANI-AuNP-GR/ITO bioelectrodes can be reused in number of times with $100 \%$ efficiency. Figure 9

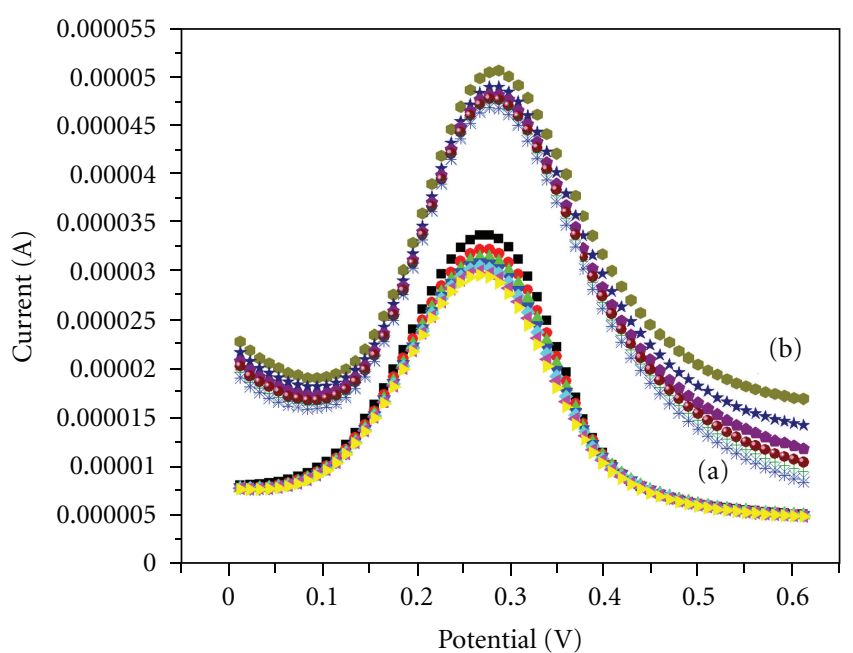

FIGURE 9: DPV curves for reusability testing (current versus potential plot with $100 \mathrm{mg} / \mathrm{dL}$ analyte for 8 times): (a) ChOx/ NSPANI-AuNP-GR/ITO and (b) ChOx-HRP/NSPANI-AuNP-GR/ ITO nanobioelectrodes.

reflects the response of bioelectrodes for 15 times testing using the same bioelectrode with $100 \mathrm{mg} / \mathrm{dL}$ cholesterol concentration in PBS solution $(50 \mathrm{mM}, 0.9 \% \mathrm{NaCl}, 5 \mathrm{mM}$ $\left[\mathrm{Fe}(\mathrm{CN})_{6}\right]^{3-/ 4-}$ at room temperature $\left(25^{\circ} \mathrm{C}\right)$. The reusability of the bioelectrodes can be attributed to robust properties of the transducer matrix. The reusability indicates that NSPANI-AuNP-GR matrix offers a favourable microenvironment for enzymes which does not cause denaturing of enzymes. The reusability can be explained by the enhanced stability of the enzymes, indicating unique electrochemical properties and biocompatibility of NSPANI-AuNP-GR/ITO electrode.

(d) Shelf Life Studies. The shelf lives of ChOx/NSPANIAuNP-GR/ITO and ChOx-HRP/NSPANI-AuNP-GR/ITO bioelectrodes have been determined by measuring the response current at regular interval of one week for about two months. Figure 10 demonstrates the shelf life of the ChOx/NSPANI-AuNP-GR/ITO and ChOx-HRP/NSPANIAuNP-GR/ITO bioelectrodes. The ChOx/NSPANI-AuNPGR/ITO and ChOx-HRP/NSPANI-AuNP-GR/ITO bioelectrodes are stored at $4^{\circ} \mathrm{C}$ when not in use. The bioelectrodes have been found to be stable up to 12 weeks without any loss in activity. 
TABLE 2: Characteristics of ChOx-HRP/NSPANI-AuNP-GR/ITO nanobioelectrode including those reported in the literature.

\begin{tabular}{|c|c|c|c|}
\hline S. no. & Components of biosensor & Characteristics & References \\
\hline \multirow{5}{*}{ (1) } & (Mat) ChOx-HRP/NSPANI-AuNP-GR/ITO & (L) upto $500 \mathrm{mg} / \mathrm{dL}$ & \multirow{5}{*}{ Present investigation } \\
\hline & (E) ChOx-HRP & (S) $4.22 \mu \mathrm{A} \mathrm{mg} \mathrm{dL}^{-1}\left(K_{m}\right) 0.01 \mathrm{mM}$ & \\
\hline & (M) ampero. versus $\mathrm{Ag} / \mathrm{AgCl}$ & (DL) $25 \mathrm{mg} / \mathrm{dL}$ & \\
\hline & & (RT) 19 secs & \\
\hline & & (SL) 2 months & \\
\hline \multirow{4}{*}{ (2) } & (Mat) $\mathrm{ChOx} / \mathrm{f}-\mathrm{G} / \mathrm{GC}$ & (L) upto $135 \mu \mathrm{M}$ & \multirow{4}{*}[44]{} \\
\hline & $\mathrm{ChOx} / \mathrm{Au} / \mathrm{f}-\mathrm{G} / \mathrm{GC}$ & (S) $314 \mathrm{nA} / \mu \mathrm{M} \mathrm{cm}^{2}$ & \\
\hline & (E) $\mathrm{ChOx}$ & (SL) 1 month & \\
\hline & (M) ampero. versus $\mathrm{Ag} / \mathrm{AgCl}$ & & \\
\hline
\end{tabular}

(Mat) ChOx/NSPANI-SDS

(E) $\mathrm{ChOx}$

(3)

(M) photometric
(L) $05-10.5 \mathrm{mM}$

(S) $9 \mathrm{mM}$

$\left(K_{m}\right) 1.32 \mathrm{mM}$

[49]

(RT) 59 secs

(SL) 5 weeks
(Mat) GR-Pt nanoparticle hybrid material

(E) $\mathrm{ChOx}, \mathrm{ChEt}$

(4)

(5)

(6)

(M) ampero. versus $\mathrm{Ag} / \mathrm{AgCl}$

\section{(Mat) GOx-HRP/MWCNT/PPY/ITO}

(E) GOx, HRP

(M) ampero. versus $\mathrm{Ag} / \mathrm{AgCl}$
(Mat) $\mathrm{ChOx} / \mathrm{NanoFe}_{3} \mathrm{O}_{4} / \mathrm{ITO}$

(E) $\mathrm{ChOx}$

(M) ampero. versus $\mathrm{Ag} / \mathrm{AgCl}$
(L) up to $12 \mathrm{mM}$

(S) $2.07 \pm 0.1 \mu \mathrm{A} / \mu \mathrm{M} / \mathrm{cm}^{2}$

$\left(K_{m}\right) 5 \mathrm{mM}$

(DL) $0.2 \mu \mathrm{M}$
(L) $1-10 \mathrm{mM}$

(S) $13.8 \mathrm{~mA} / \mu \mathrm{M}$

$\left(K_{m}\right) 0.52 \mathrm{mM}$

(DL) $0.1 \mathrm{mM}$

(RT) 10 secs

(SL) 5 weeks
(L) $2.5-400 \mathrm{mg} / \mathrm{dL}$

(S) $86 \Omega / \mathrm{mg} / \mathrm{dL} / \mathrm{cm}^{2}$

$\left(K_{m}\right) 0.8 \mathrm{mg} / \mathrm{dL}$

(DL) $0.25 \mathrm{mg} / \mathrm{dL}$

(RT) $25 \mathrm{secs}$

(SL) 55 days

(L) $10-500 \mathrm{mg} / \mathrm{dL}$

(S) $2.12 \mu \mathrm{A} / \mathrm{mM}$

$\left(K_{m}\right) 0.052 \mathrm{mM}$

(DL) $0.1 \mathrm{mM}$

(RT) 10 secs

(SL) 10 weeks

(L) $25-500 \mathrm{mg} / \mathrm{dL}$

(S) $1.3 \times 10^{-3} \mathrm{~mA} \mathrm{mg}^{-1} \mathrm{dL}$
$\left(K_{m}\right) 2.5 \mathrm{mM}$
(RT) 10 secs
(SL) 12 weeks

[51]
(M) ampero. versus $\mathrm{Ag} / \mathrm{AgCl}$

\section{Ox/PANI-NS/ITO}

(E) $\mathrm{ChOx}$

( (Mat) material; (E): enzyme; (M): method; (DL): detection limit; (L): linearity; (SL): shelf life; (RT): response time; $(\mathrm{S})$ : sensitivity; $\left(K_{m}\right)$ : Michaelis-
Menton constant; (f-G): functionalized graphene nanoplatelets; (Au/f-G): gold-nanoparticle-decorated f-G; (NSPANI): nanostructured polyaniline; $(\mathrm{SDS})$ : sodium dodecyl sulphate; (MWCNT/PPY/ITO): carboxy-modified multiwalled carbon nanotubes (MWCNT) and polypyrrole (PPY) nanocomposite film; $\left(\mathrm{NanoFe}_{3} \mathrm{O}_{4}\right)$ : nanostructured iron oxide; $\left(\mathrm{SiO}_{2}\right)$ : silica; (CHIT): chitosan; (PANI-NS): polyaniline nanospheres.

3.5. Comparative Evaluation of Mono- and Bienzymatic Biosensor. Table 1 represents a comparative evaluation of mono- and bienzymatic biosensor performance. It has been found that bienzymatic electrodes ChOx-HRP/NSPANIAuNP-GR/ITO exhibit better performance in terms of linearity, shelf life, response time, and sensitivity as compared to monoenzyme-based ChOx/NSPANI-AuNP-GR/ITO electrode. The immobilization of the $\mathrm{ChOx}$ together with horseradish peroxidase (HRP) is thought to either help the protein to assume a favorable orientation or to make possible conducting channels between the prosthetic groups and the electrode surface. Both can reduce the effective electron 
TABLE 3: Results from the blood serum samples using ChOx/NSPANI-AuNP-GR/ITO and ChOx-HRP/NSPANI-AuNP-GR/ITO biosensors.

\begin{tabular}{|c|c|c|c|c|c|c|}
\hline $\begin{array}{l}\text { Sample } \\
\text { no. }\end{array}$ & $\begin{array}{l}\text { Chox/NSPANI/Au-GR/ITO } \\
\text { (amperometric) }\end{array}$ & $\begin{array}{l}\text { Chox/NSPANI/Au-GR/ITO } \\
\text { (photometric) }\end{array}$ & Error (\%) & $\begin{array}{c}\text { Chox-HRP/ } \\
\text { NSPANI/Au-GR/ITO } \\
\text { (amperometric) }\end{array}$ & $\begin{array}{c}\text { Chox- } \\
\text { HRP/NSPANI/Au- } \\
\text { GR/ITO } \\
\text { (photometric) }\end{array}$ & Error (\%) \\
\hline 1 & 225 & 218 & 3 & 230 & 226 & 1.7 \\
\hline 2 & 158 & 149 & 6 & 162 & 160 & 1.2 \\
\hline 3 & 182 & 178 & 2 & 186 & 183 & 1.6 \\
\hline 4 & 306 & 298 & 3 & 311 & 307 & 1.3 \\
\hline 5 & 76 & 69 & 9 & 80 & 78 & 2.5 \\
\hline
\end{tabular}

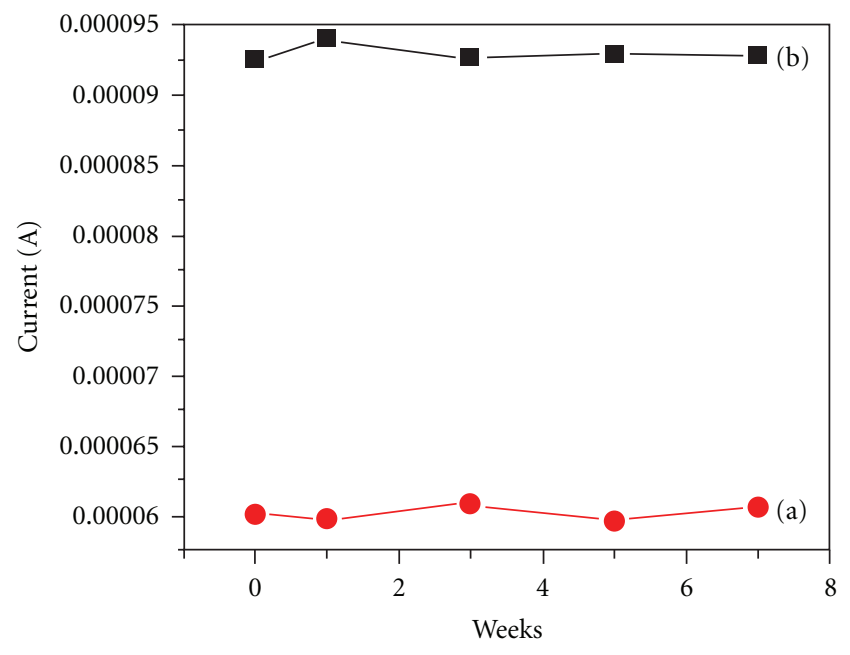

Figure 10: Results of shelf life of (a) ChOx/NSPANI-AuNP-GR/ITO and (b) ChOx-HRP/NSPANI-AuNP-GR/ITO nanobioelectrodes.

transfer distance and thereby facilitate the charge transfer between the electrode and the enzyme [49].

Table 2 shows the characteristics of ChOx-HRP/ NSPANI-AuNP-GR/ITO nanobioelectrode including those reported in the literature for ChOx-HRP system. It is profound that bioenzymatic electrodes ChOx-HRP/NSPANIAuNP-GR/ITO offer unique characteristics with respect to reusability, shelf life, and very low $K_{m}$ value of $0.01 \mathrm{mM}$.

3.6. Blood Serum Testing. The response of the ChOx/ NSPANI-AuNP-GR/ITO and ChOx-HRP/NSPANI-AuNPGR/ITO bioelectrodes to the cholesterol in human blood serum has been investigated by amperometric and photometric studies, and results were compared. Five serum samples obtained from pathological lab were analyzed. Table 3 shows the results from the blood serum samples using ChOx/NSPANI-AuNP-GR/ITO and ChOx-HRP/NSPANIAuNP-GR/ITO biosensors. Both bioelectrodes provide excellent performance in evaluation of cholesterol in blood serum samples which may be due to the high electrocatalytic effect of NSPANI-AuNP-GR/ITO nanocomposite electrode. The results obtained from amperometric determination of free cholesterol in blood serum are compared with the results obtained from the photometric response studies considering as standard values of free blood cholesterol. The results obtained for ChOx-HRP/NSPANI-AuNP-GR/ITO by using amperometric and photometric studies are very close to each other with minimum error while ChOx/NSPANI-AuNPGR/ITO shows comparatively higher deviation.

\section{Conclusion}

Gold-nanoparticle-decorated graphene-nanostructured polyaniline nanobioelectrodes have been fabricated from the NSPANI-AuNP-GR nanodispersion as synthesized via in situ polymerization, using electrodeposition technique, for the development of reusable cholesterol biosensor. Both single ChOx and ChOx-HRP-based biosensors are developed using covalent bonding through glutaraldehyde. The bienzymebased nanocomposite bioelectrodes (ChOx-HRP/NSPANIAuNP-GR/ITO) offer better performance in terms of detection limit, sensitivity, and response time than single enzyme system. This is attributed to the presence of HRP along with $\mathrm{ChOx}$ to enhance the overall biochemical reaction. It has been shown that this nanocomposite bioelectrode can be used to estimate cholesterol in blood serum samples. The unique features of the ChOx-HRP/NSPANI-AuNPGR/ITO nanocomposite bioelectrode lie with the novelty of fabrication, minimum interference, very low $K_{m}$ value, low response time, excellent reusability, and its usefulness for blood serum samples. The large specific surface area, excellent conductivity, stable, and reliable redox properties of NSPANI-AuNP-GR nanocomposite film allow the rapid transmit of electron and enhance current response for the immobilized enzymes. It should be interesting to utilize these nanocomposite electrodes for development of other biosensors.

\section{Acknowledgments}

The authors are thankful to Dr. A. K. Chauhan (Founder President, Amity University, Uttar Pradesh) for providing the platform of research at the Amity University Uttar Pradesh, and they also offer their sincere thanks to Dr. (Mrs.) Balwinder Shukla Pro Vice Chancellor, Professor A. K. Srivastava, Director General, AIB, Dr. R. P. Singh, Director, AINT AUUP for their constant support and encouragement. They acknowledge the financial assistance received from the Department of Biotechnology, Government of India (Project no. BTPR 11123/MD/32/41/2008 DBT), India. 


\section{References}

[1] A. K. Geim, "Graphene: status and prospects," Science, vol. 324, no. 5934, pp. 1530-1534, 2009.

[2] Y. Zhang, Y. W. Tan, H. L. Stormer, and P. Kim, "Experimental observation of the quantum Hall effect and Berry's phase in graphene," Nature, vol. 438, no. 7065, pp. 201-204, 2005.

[3] C. N. R. Rao, K. Biswas, K. S. Subrahmanyam, and A. Govindaraj, "Graphene, the new nanocarbon," Journal of Materials Chemistry, vol. 19, no. 17, pp. 2457-2469, 2009.

[4] M. D. Stoller, S. Park, Z. Yanwu, J. An, and R. S. Ruoff, "Graphene-Based ultracapacitors," Nano Letters, vol. 8, no. 10, pp. 3498-3502, 2008.

[5] J. S. Bunch, A. M. Van Der Zande, S. S. Verbridge et al., "Electromechanical resonators from graphene sheets," Science, vol. 315, no. 5811, pp. 490-493, 2007.

[6] Z. Liu, J. T. Robinson, X. Sun, and H. Dai, "PEGylated nanographene oxide for delivery of water-insoluble cancer drugs," Journal of the American Chemical Society, vol. 130, no. 33, pp. 10876-10877, 2008.

[7] P. K. Ang, W. Chen, A. T. S. Wee, and P. L. Kian, "Solutiongated epitaxial graphene as $\mathrm{pH}$ sensor," Journal of the American Chemical Society, vol. 130, no. 44, pp. 14392-14393, 2008.

[8] F. Schedin, A. K. Geim, S. V. Morozov et al., "Detection of individual gas molecules adsorbed on graphene," Nature Materials, vol. 6, no. 9, pp. 652-655, 2007.

[9] K. S. Novoselov, E. McCann, S. V. Morozov et al., "Unconventional quantum Hall effect and Berry's phase of $2 \pi$ in bilayer graphene," Nature Physics, vol. 2, no. 3, pp. 177-180, 2006.

[10] Y. Zhang, Y. W. Tan, H. L. Stormer, and P. Kim, "Experimental observation of the quantum Hall effect and Berry's phase in graphene," Nature, vol. 438, no. 7065, pp. 201-204, 2005.

[11] K. S. Novoselov, A. K. Geim, S. V. Morozov et al., "Electric field in atomically thin carbon films," Science, vol. 306, no. 5696, pp. 666-669, 2004.

[12] K. Kanghyun, J. P. Hyung, B. C. Woo, J. K. Kook, T. K. Gyu, and S. Y. Wan, "Electric property evolution of structurally defected multilayer grapheme," Nano Letters, vol. 8, no. 10, pp. 30923096, 2008

[13] C. Lee, X. Wei, J. W. Kysar, and J. Hone, "Measurement of the elastic properties and intrinsic strength of monolayer graphene," Science, vol. 321, no. 5887, pp. 385-388, 2008.

[14] H. Chen, M. B. Müller, K. J. Gilmore, G. G. Wallace, and D. Li, "Mechanically strong, electrically conductive, and biocompatible graphene paper," Advanced Materials, vol. 20, no. 18 , pp. 3557-3561, 2008.

[15] M. Segal, "Selling graphene by the ton," Nature Nanotechnology, vol. 4, p. 612, 2009.

[16] J. Janata and M. Josowicz, "Conducting polymers in electronic chemical sensors," Nature Materials, vol. 2, p. 19, 2002.

[17] J. Huang, S. Virji, B. H. Weiller, and R. B. Kaner, "Nanostructured Polyaniline Sensors," Chemistry, vol. 10, no. 6, pp. 13141319, 2004.

[18] J. Liu, Y. Lin, L. Liang et al., "Templateless assembly of molecularly aligned conductive polymer nanowires: a new approach for oriented nanostructures," Chemistry, vol. 9, no. 3, pp. 604-611, 2003.

[19] C. Dhand, S. K. Arya, S. P. Singh, B. P. Singh, M. Datta, and B. D. Malhotra, "Preparation of polyaniline/multiwalled carbon nanotube composite by novel electrophoretic route," Carbon, vol. 46, no. 13, pp. 1727-1735, 2008.

[20] M. Nandi, R. Gangopadhyay, and A. Bhaumik, "Mesoporous polyaniline having high conductivity at room temperature,"
Microporous and Mesoporous Materials, vol. 109, no. 1-3, pp. 239-247, 2008.

[21] Deepshikha and T. Basu, Journal of Experimental Nanoscience. In press.

[22] Deepshikha and T. Basu, "A review on synthesis and characterization of nanostructured conducting polymers (NSCP) and application in biosensors," Analytical Letters, vol. 44, no. 6, pp. 1126-1171, 2011.

[23] E. Boisselier and D. Astruc, "Gold nanoparticles in nanomedicine: preparations, imaging, diagnostics, therapies and toxicity," Chemical Society Reviews, vol. 38, no. 6, pp. 1759-1782, 2009.

[24] J. Perez-Juste, I. Pastoriza-Santos, L. M. Liz-Marzan, and P. Mulvaney, "Gold nanorods: Synthesis, characterization and applications," Coordination Chemistry Reviews, vol. 249, no. 17-18, pp. 1870-1901, 2005.

[25] S. G. Penn, L. He, and M. J. Natan, "Nanoparticles for bioanalysis," Current Opinion in Chemical Biology, vol. 7, pp. 609-615, 2003.

[26] G. H. Lu, L. E. Ocola, and J. H. Chen, "Gas detection using low-temperature reduced graphene oxide sheets," Applied Physics Letters, vol. 94, Article ID 083111, 2009.

[27] J. Lu, I. Do, L. T. Drzal, R. M. Worden, and I. Lee, "Nanometal-decorated exfoliated graphite nanoplatelet based glucose biosensors with high sensitivity and fast response," ACS Nano, vol. 2, no. 9, pp. 1825-1832, 2008.

[28] J. Zhang, J. Zhang, F. Zhang et al., "Graphene oxide as a matrix for enzyme immobilization," Langmuir, vol. 26, no. 9, pp. 6083-6085, 2010.

[29] M. Zhou, Y. Zhai, and S. Dong, "Electrochemical sensing and biosensing platform based on chemically reduced graphene oxide," Analytical Chemistry, vol. 81, p. 5603, 2009.

[30] Y. Liu, D. Yu, C. Zeng, Z. Miao, and L. Dai, "Biocompatible graphene oxide-based glucose biosensors," Langmuir, vol. 26, no. 9, pp. 6158-6160, 2010.

[31] D. Du, Z. Zou, Y. Shin et al., "Sensitive immunosensor for cancer biomarker based on dual signal amplification strategy of graphene sheets and multienzyme functionalized carbon nanospheres," Analytical Chemistry, vol. 82, no. 7, pp. 29892995, 2010.

[32] Y. Wang, Y. Shao, D. W. Matson, J. Li, and Y. Lin, "Nitrogendoped graphene and its application in electrochemical biosensing," ACS Nano, vol. 4, no. 4, pp. 1790-1798, 2010.

[33] Y. Shao, J. Wang, H. Wu, J. Liu, I. A. Aksay, and Y. Lin, "Graphene based electrochemical sensors and biosensors: a review," Electroanalysis, vol. 22, no. 10, pp. 1027-1036, 2010.

[34] S. Myung, A. Solanki, C. Kim, J. Park, K. S. Kim, and K. B. Lee, "Graphene-encapsulated nanoparticle-based biosensor for the selective detection of cancer biomarkers," Advanced Materials, vol. 23, no. 19, pp. 2221-2225, 2011.

[35] P. Norouzi, H. Ganjali, B. Larijani, M. R. Ganjali, F. Faridbod, and H. A. Zamani, "A glucose biosensor based on nanographene and $\mathrm{ZnO}$ nanoparticles using FFT continuous cyclic voltammetry," International Journal of Electrochemical Science, vol. 6, p. 5189, 2011.

[36] R. S. Dey and C. R. Raj, "Development of an amperometric cholesterol biosensor based on graphene-Pt nanoparticle hybrid material," Journal of Physical Chemistry C, vol. 114, no. 49, pp. 21427-21433, 2010.

[37] M. Yang, Y. Yang, Y. Liu, G. Shen, and R. Yu, "Platinum nanoparticles-doped sol-gel/carbon nanotubes composite electrochemical sensors and biosensors," Biosensors and Bioelectronics, vol. 21, p. 1125, 2006. 
[38] T. Kuila, T. S. Bose, P. Khanra, A. K. Mishra, N. H. Kim, and J. H. Lee, "Recent advances in graphene-based biosensors," Biosensors and Bioelectronics, vol. 15, pp. 4637-4648, 2011.

[39] R. Antiochia and L. Gorton, "Development of a carbon nanotube paste electrode osmium polymer-mediated biosensor for determination of glucose in alcoholic beverages," Biosensors and Bioelectronics, vol. 22, no. 11, pp. 2611-2617, 2007.

[40] S. Liu, J. Yu, and H. Ju, "Renewable phenol biosensor based on a tyrosinase-colloidal gold modified carbon paste electrode," Journal of Electroanalytical Chemistry, vol. 540, p. 61, 2003.

[41] J. Chen, J. Tang, F. Yan, and H. Ju, "A gold nanoparticles/solgel composite architecture for encapsulation of immunoconjugate for reagentless electrochemical immunoassay," Biomaterials, vol. 27, no. 10, pp. 2313-2321, 2006.

[42] Deepshikha and T. Basu, "Synthesis and characterization of nanocomposites based on polyaniline-gold/graphene nanosheets ," Applied Nanoscience. In press.

[43] X. Wu, S. Qi, J. He, B. Chen, and G. Duan, "Synthesis of high conductivity Polyaniline/Ag/graphite nanosheet composites via ultrasonic technique," Journal of Polymer Research, vol. 17, p. 751, 2010.

[44] S. S. J. Aravind, T. T. Baby, T. Arockiadoss, R. B. Rakhi, and S. Ramaprabhu, "A cholesterol biosensor based on gold nanoparticles decorated functionalized graphene nanoplatelets," Thin Solid Films, vol. 519, no. 16, pp. 5667-5672, 2011.

[45] A. Wisitsoraat, P. Sritongkham, C. Karuwan, D. Phokharatkul, T. Maturos, and A. Tuantranont, "Fast cholesterol detection using flow injection microfluidic device with functionalized carbon nanotubes based electrochemical sensor," Biosensors and Bioelectronics, vol. 26, no. 4, pp. 1514-1520, 2010.

[46] K. Singh, P. R. Solanki, T. Basu, and B. D. Malhotra, "Polypyrrole/multiwalled carbon nanotubes-based biosensor for cholesterol estimation," Polymers for Advanced Technologies, vol. 23, no. 7, pp. 1084-1091, 2012.

[47] K. Singh, T. Basu, P. R. Solanki, and B. D. Malhotra, "Poly (pyrrole-co-N-methyl pyrrole) for application to cholesterol sensor," Journal of Materials Science, vol. 44, no. 4, pp. 954961, 2009.

[48] P. R. Solanki, S. K. Arya, S. P. Singh, M. K. Pandey, and B. D. Malhotra, "Application of electrochemically prepared poly$\mathrm{N}$-methylpyrrole-p-toluene sulphonate films to cholesterol biosensor," Sensors and Actuators B, vol. 123, no. 2, pp. 829839, 2007.

[49] Deepshikha and T. Basu, "Synthesis, characterization and application of nanostructured conducting polyaniline to biosensing," Journal of Bionanoscience, vol. 4, pp. 38-44, 2010.

[50] K. Singh, B. P. Singh, R. Chauhan, and T. Basu, "Fabrication of amperometric bienzymatic glucose biosensor based on MWCNT tube and polypyrrole multilayered nanocomposite," Journal of Applied Polymer Science, vol. 125, supplement 1, pp. E235-E246, 2012.

[51] A. Kaushik, P. R. Solanki, K. Kaneto, C. G. Kim, S. Ahmad, and B. D. Malhotra, "Nanostructured iron oxide platform for impedimetric cholesterol detection," Electroanalysis, vol. 22, no. 10, pp. 1045-1055, 2010.

[52] P. R. Solanki, A. Kaushik, A. A. Ansari, A. Tiwari, and B. D. Malhotra, "Multi-walled carbon nanotubes/sol-gel-derived silica/chitosan nanobiocomposite for total cholesterol sensor," Sensors and Actuators B, vol. 137, no. 2, pp. 727-735, 2009.

[53] C. Dhand, M. Das, G. Sumana et al., "Preparation, characterization and application of polyaniline nanospheres to biosensing," Nanoscale, vol. 2, no. 5, pp. 747-754, 2010. 

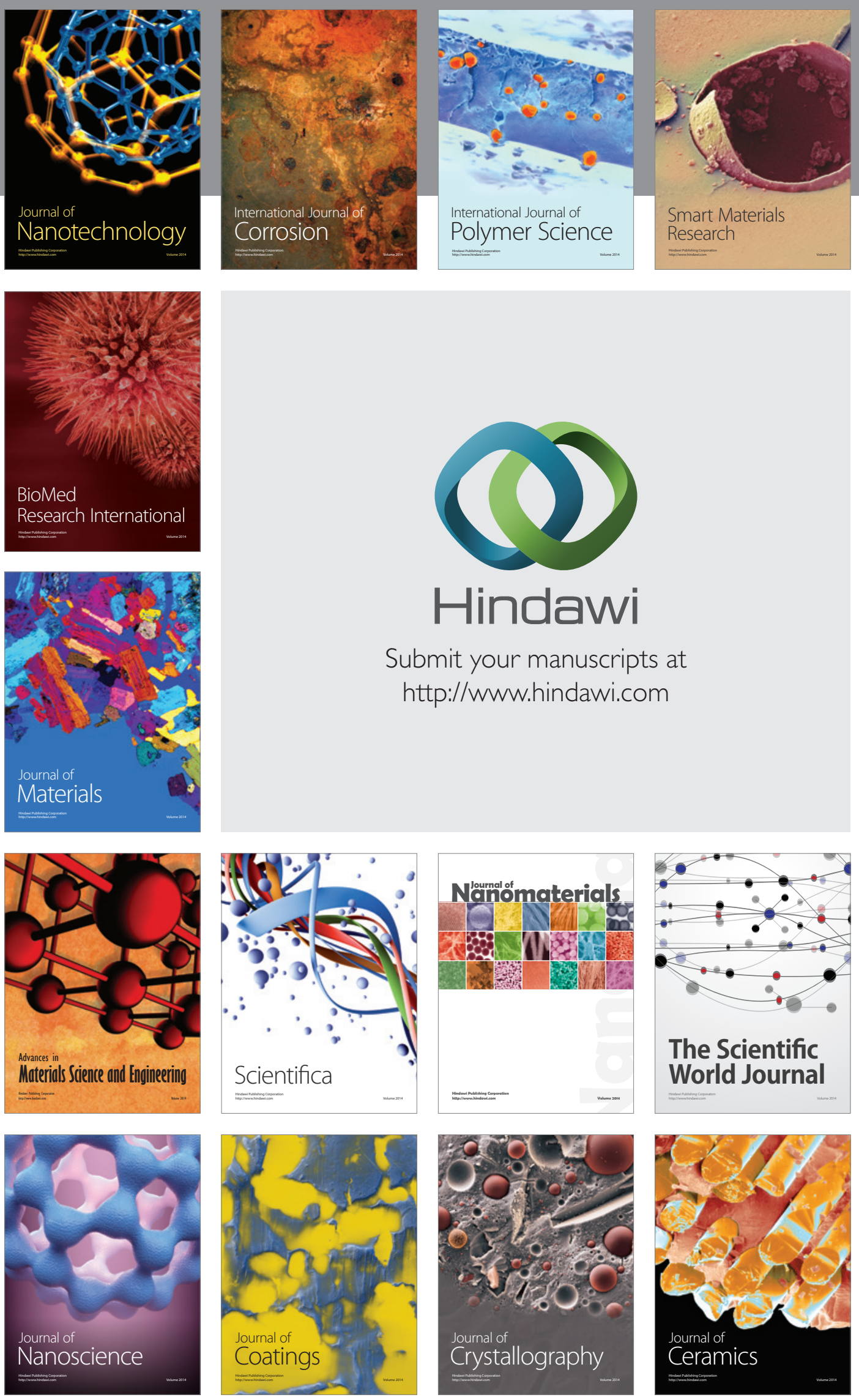

The Scientific World Journal

Submit your manuscripts at

http://www.hindawi.com

\section{World Journal}

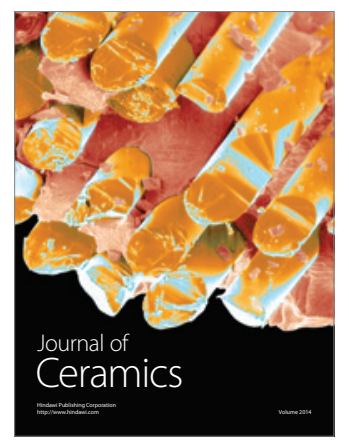

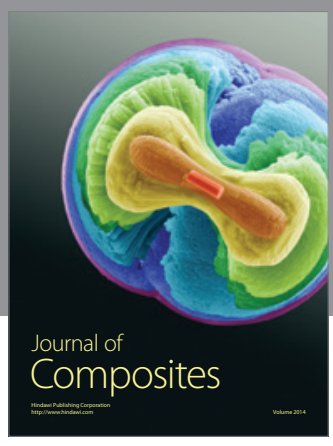
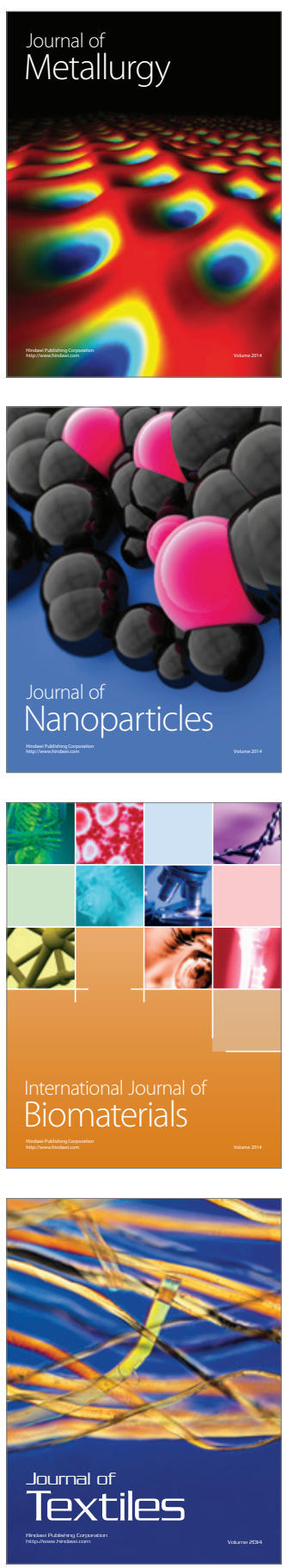